\title{
Sedimentary evolution of Fuyu Oil layer in 401 block, Sanzhao Depression, Songliao Basin
}

\author{
Xin Liü, a Zhaonian Chen ${ }^{1, b}$, Lei Liü, c \\ ${ }^{1}$ School of Energy Resources, China University of Geosciences, Beijing 100083, China \\ ${ }^{2}$ No.7 oil extraction, Daqing oil field, Daqing 163517, China \\ a253710226@qq.com, b517033595@qq.com, cliulei543@163.com
}

Keywords: Songliao Basin, Sanzhao Depression, Fuyu oil layer, sedimentary evolution.

\begin{abstract}
This paper takes Sanzhao Depression in Songliao Basin as the research target. Fuyu oil layer is in the 4th member of Quantou formation, Lower Cretaceous. The target layer in research area is mainly a set of shallow-water delta deposition, experienced the sedimentary evolution process from Delta plain to Delta front, reflect the water level changed from deep to shallow and back to deep. Because of the distributary channel frequently swing, single sand body thin thickness, study of micro facies must be carried out to guide further petroleum development. In the case of lack of core data, this study take advantage of seismic and logging data to analysis the micro facies of each reservoir group and sedimentary evolution of Fuyu oil layer. This paper proposes: 1. FIII, F II, F I 3 and F I 2 sub-layer of Fuyu oil layer in research area is mainly Delta plain deposition; F I 1 sub-layer is mainly Delta front deposition. 2. During the sedimentary period of FIII, F II and F I 3 sub-layer, the climate changed from humid to dry, sediment supply gradually increased; During the sedimentary period of F I 2 and F I 1 sub-layer, the climate changed from dry to humid, sediment supply gradually decreased.
\end{abstract}

\section{Introduction}

Songliao Basin is one of the oil \& gas richest continental sedimentary basins all around the world. Since obtained industry oil flow in the 1960s, lots of geological work has been done by scholars. The 4th member of Quantou formation is mainly shallow-water delta deposition, includes two sub facies: Delta front and Delta plain. It is a third order sequence which can be divided into three fourth order sequence [1]. Overpressure in the 1st member of Qingshankou formation was the force of hydrocarbon migration downward and opened faults were good path [2].

This paper on the basis of a comprehensive collection of seismic and logging data, deeply investigated the facies of each sub-layer, analyzed the sedimentary evolution during sedimentary period of 4th member of Quantou formation.

\section{Geological setting}

The target layer is in 4th member of Quantou formation in lower Cretaceous. The lower Cretaceous is composed of Huoshiling, Shahezi, Yingcheng, Denglouku and Quantou Formations in the study area, while the upper Cretaceous is composed of Qingshankou, Yaojia, Nenjiang, Sifangtai and Mingshui Formations. From late Jurassic to Quaternary, the biggest tectonic deformation happened during the sedimentary period between Nenjiang formation and Mingshui formation.

The main trend of the formations in the study area inclined from southwest to northeast. Faults near south-north trending complicated the tectonic framework. From the Quantou formation period to the late Nengjiang formation period, the study area is a big negative structure presenting as stable depression sedimentation. In the local tensional tectonic background, the deposition is stable with little change in formation thickness. In the late Nengjiang formation period, the study area was non-equilibrium uplifted, the basin started to shrink with large scale folds and uplifts. 


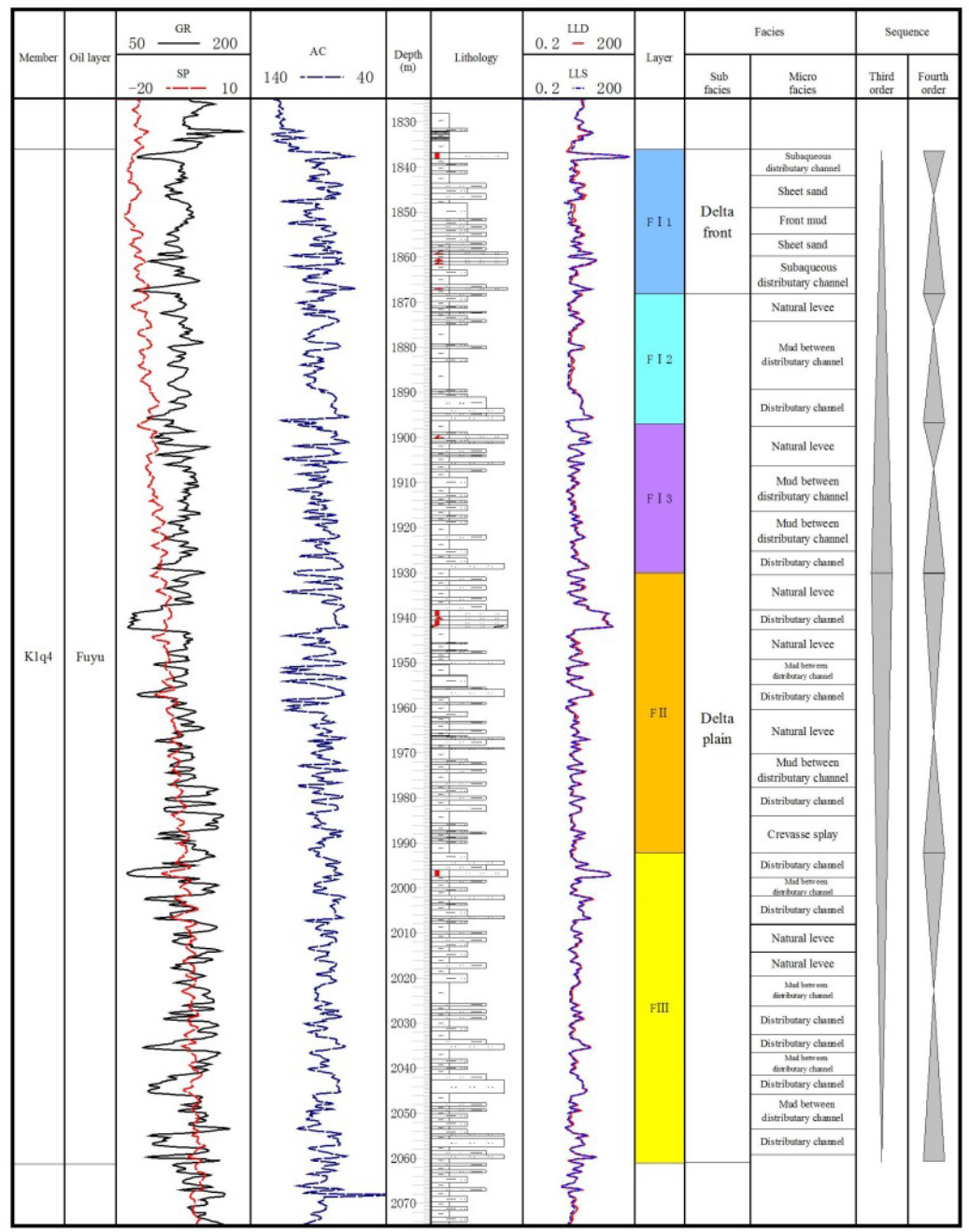

Fig. 1 Facies of Well b4

Fuyu oil layer is in the 4th member of Quantou formation, Lower Cretaceous. During the early sedimentary period of the 4th member of Quantou formation, climate changed from wet to dry, large rivers developed in edge basin and converged in the central basin, widely deposited fluvial facies and delta facies in the entire basin. During the middle and late sedimentary period of the 4th member of Quantou formation, water level gradually became deeper, the study area developed Delta plain and Delta front deposition.

\subsection{Single well facies}

Fuyu oil layer is in the 4th member of Quantou formation, on the basis of the identification of the base-level cycle, it can be divided into three mid-term cycles and further divided into five short-term cycles [3]. In this article, Fuyu oil layer is divided into five sub-layers: FIII, F II , F I 3, F I 2 and F I 1.

By analyzing the single well facies of 14 exploration wells in the research area, concluded: FIII, F II, F I 3 and F I 2 sub-layer of Fuyu oil layer is mainly Delta plain deposition, the micro facies include distributary channel, crevasse splay, natural levee and mud between distributary channel; F I 1 is mainly Delta front deposition, the micro facies include subaqueous distributary channel and sheet sand, lack of channel mouth bar (Fig. 1).

\subsection{Plain facies}

Due to the situation that there are only 14 exploration wells in study area at the present, this paper based on the analysis of single well micro facies, and make full use of 3D seismic data to carry out the plane facies of each sub-layer, further, accomplish the research of sedimentary evolution. 
RMS amplitude is used to research plane facies in this study. RMS amplitude reflects the variation of wave impedance, layer thickness, rock composition, porosity and fluid composition in target layer, it can be used to identify abnormal amplitude or sequence characteristics sequence analysis; can be used to track the stratigraphic features, such as delta, channel or special lithology; also be used to identify changes in lithology, unconformity, gas, fluid accumulation and so on [4]. So this study is basis on the RMS amplitude attribute, combined with logging data to research sedimentary micro facies, and use the RMS amplitude attribute to draw plane sedimentary micro facies of each sub-layer.

(1) FIII sub-layer

Humid climate of this period, the lake is deep, with weak source supply, mainly developed shallow delta plain sub-facies, micro facies include distributary channel, crevasse splay and mud between distributary channel. The distribution of sand bodies is controlled by the distributary channel. The main sediment source of the study area was from the north region (Fig. 2, 3).

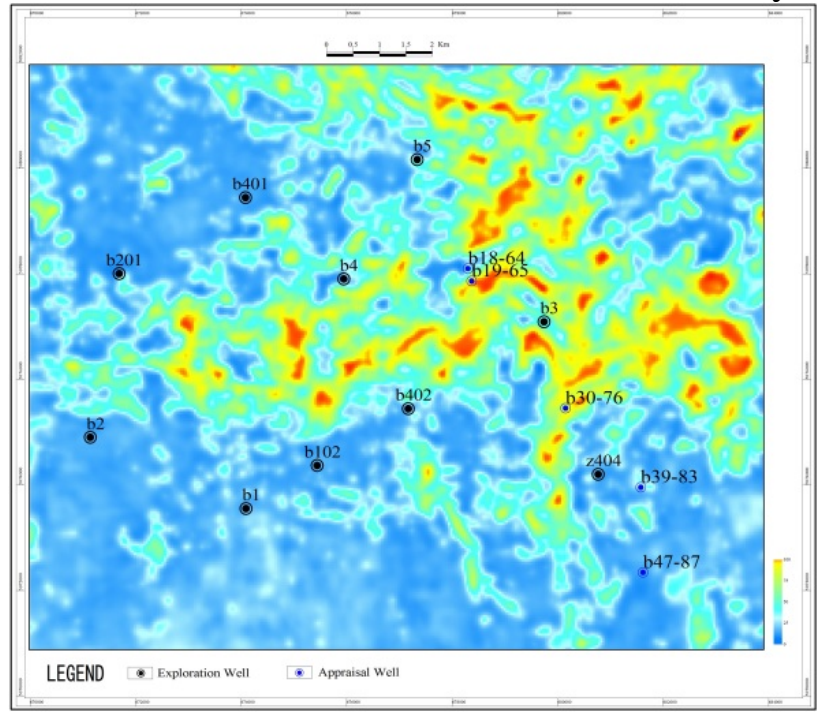

Fig. 2 RMS amplitude of FIII sub-layer

(2) F II sub-layer

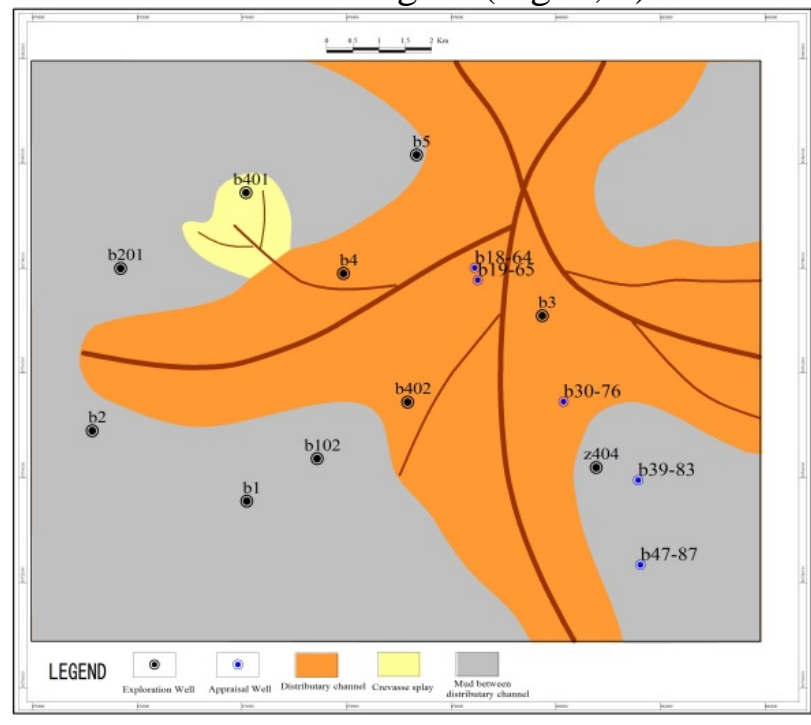

Fig. 3 Plain facies of FIII sub-layer

The climate of this period changed from wet to dry, the shoreline retreated, source supply gradually strengthen, the scale of delta gradually increased, the study area mainly developed delta plain sub-facies deposition, the sedimentary micro facies types mainly include distributary channel and mud between distributary channel. The main sediment source of the study area was from the southwest region (Fig. 4, 5).

(3) F I 3 sub-layer

During this period, dry climate continues, lake range shrank to minimum, with the strongest source supply, and the delta developed to the largest. The study area mainly developed delta plain sub-facies deposition, the sedimentary micro facies include distributary channel, natural levee and mud between distributary channel. Sediment source in the study area are derived mainly from the southwest region (Fig. 6, 7). 


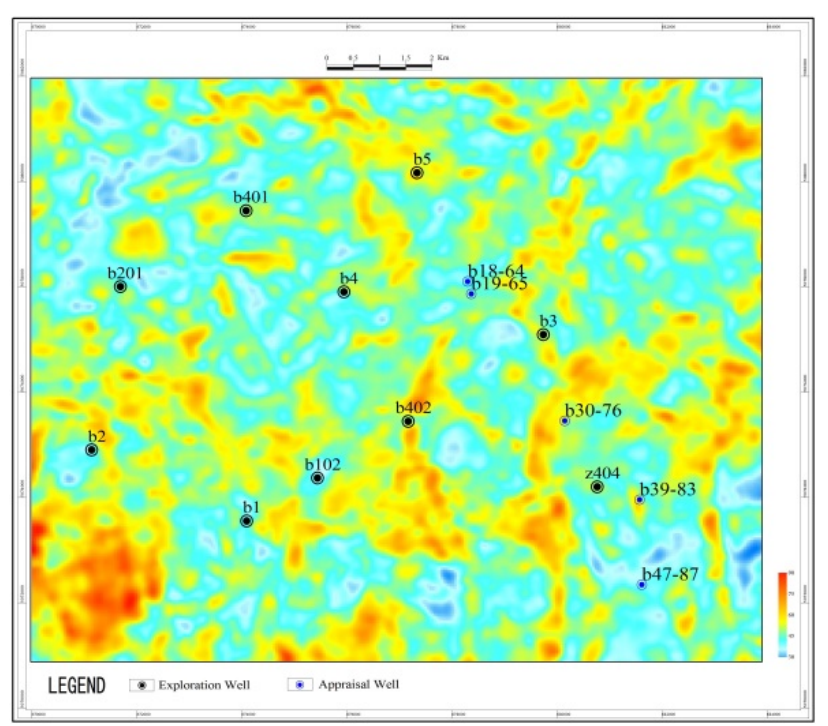

Fig. 4 RMS amplitude of F II sub-layer

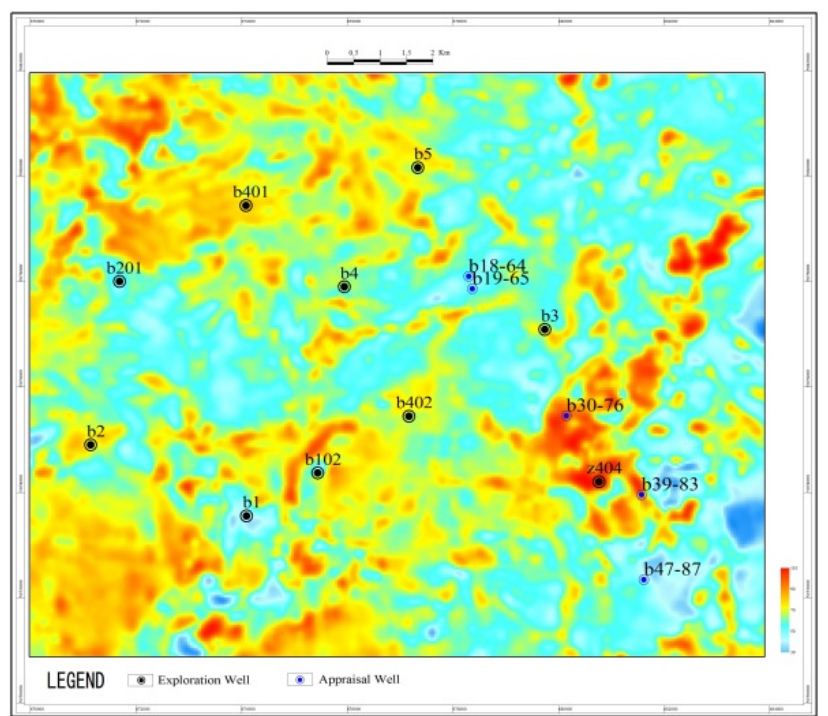

Fig. 6 RMS amplitude of F I 3 sub-layer

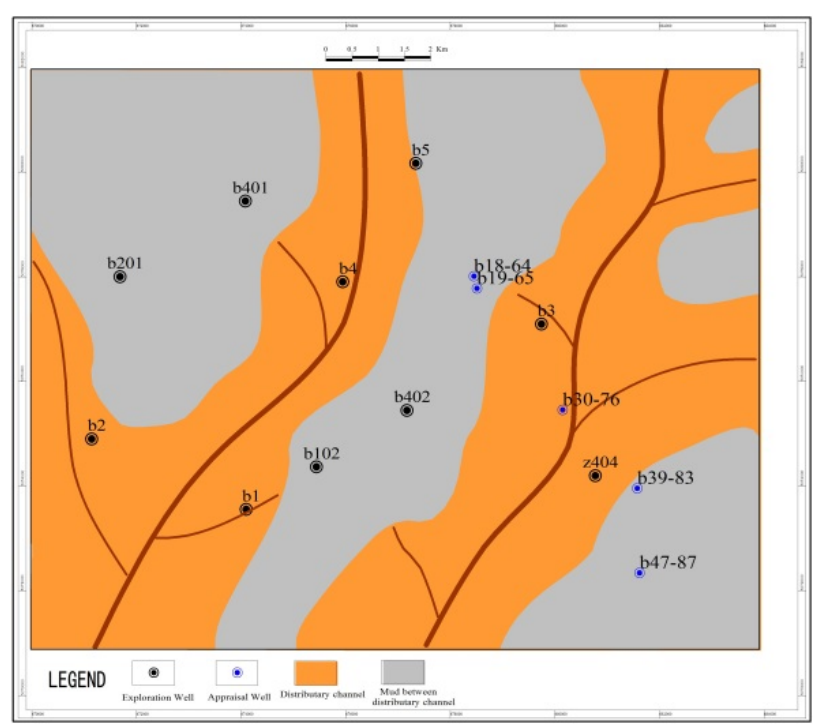

Fig. 5 Plain facies of F II sub-layer

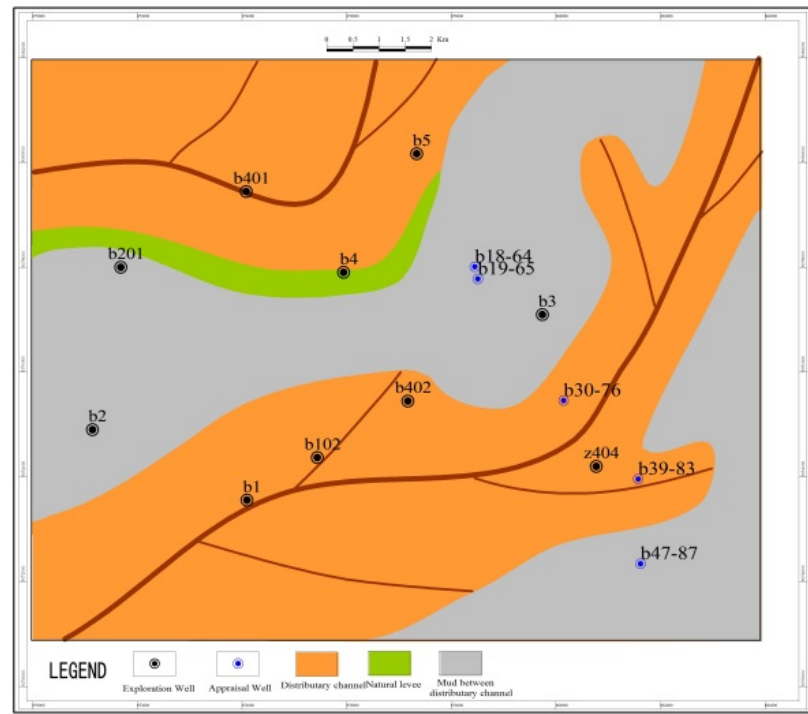

Fig. 7 Plain facies of F I 3 sub-layer

(4) F I 2 sub-layer

During this period, the climate changes from dry to wet, lake range expanding gradually and sediment source supply remains strong, the study area mainly developed delta plain sub-facies deposition, the sedimentary micro facies include distributary channel and mud between distributary channel. Sediment source in the study area are derived mainly from the south region (Fig. 8, 9).

(5) F I 1 sub-layer

During this period, the climate is humid, lake level expansion rapidly, source supply weaken, the lake range reduced to the smallest. The study area mainly developed delta front sub-facies deposition, sedimentary micro facies include underwater distributary channel and sheet sand, channel mouth bar is not developed, because of the sediment source is adequate, the terrain is flat, with highly constructive, performance as, the previously deposited channel mouth bar, transformed into sheet sand, made the mouth bar is not easy to preserve, moreover, the water power of shallow lake is weak, but the form of channel mouth bar need stronger power, so the sedimentary of channel mouth bar in the study area is limited. The main sediment source of the study area was from the southwest region (Fig. 10, 11). 


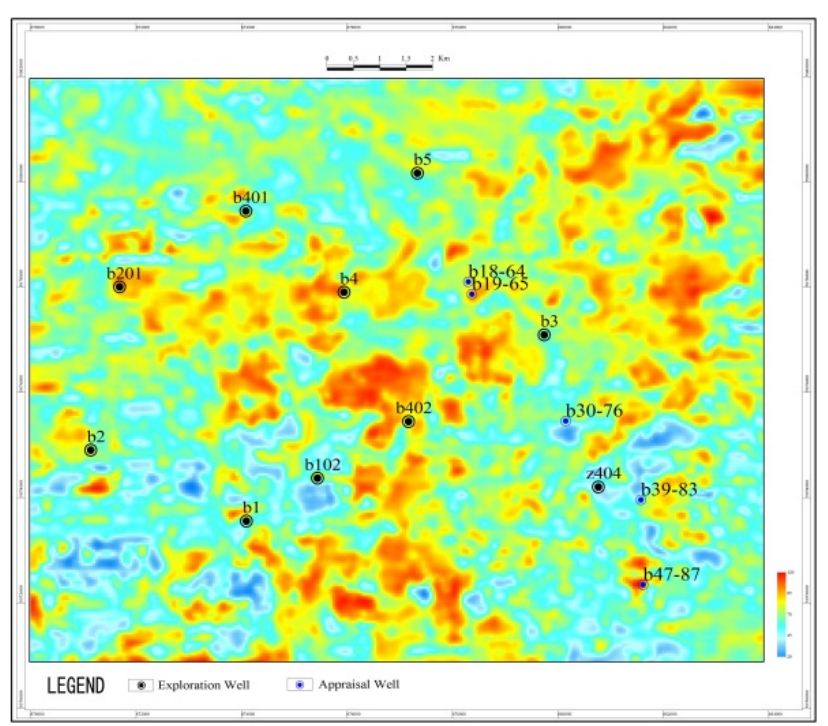

Fig. 8 RMS amplitude of F I 2 sub-layer

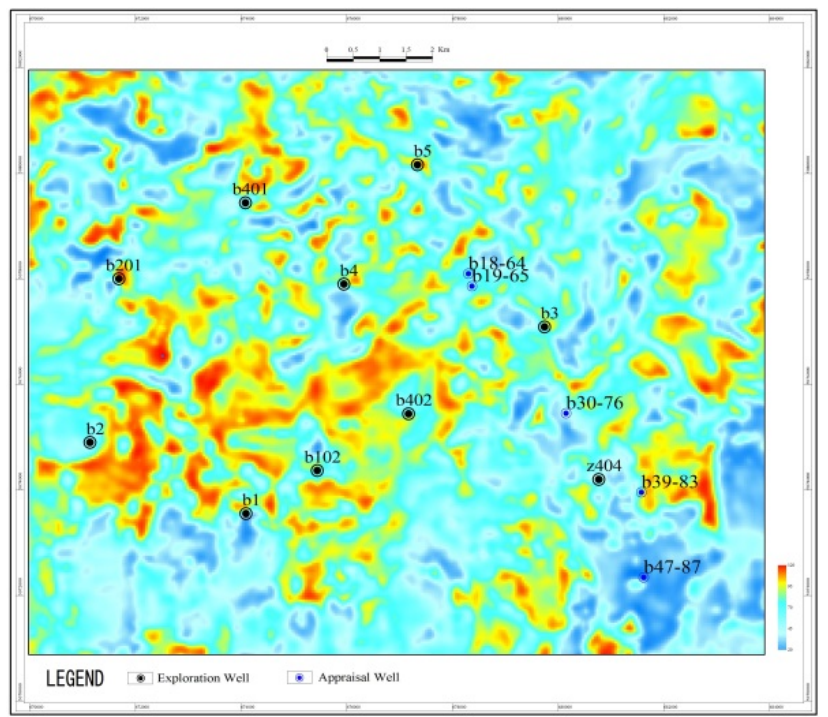

Fig. 10 RMS amplitude of F I 1 sub-layer

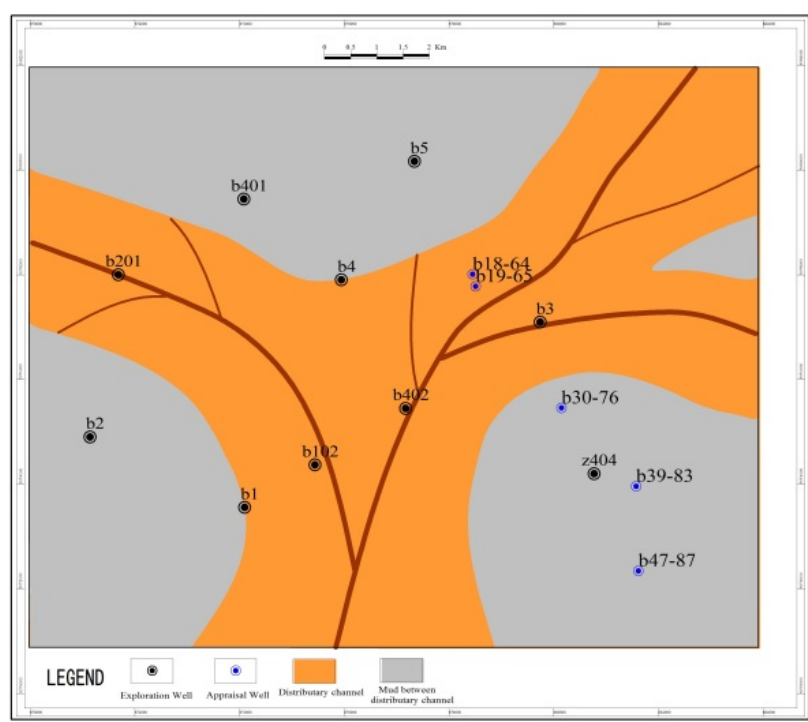

Fig. 9 Plain facies of F I 2 sub-layer

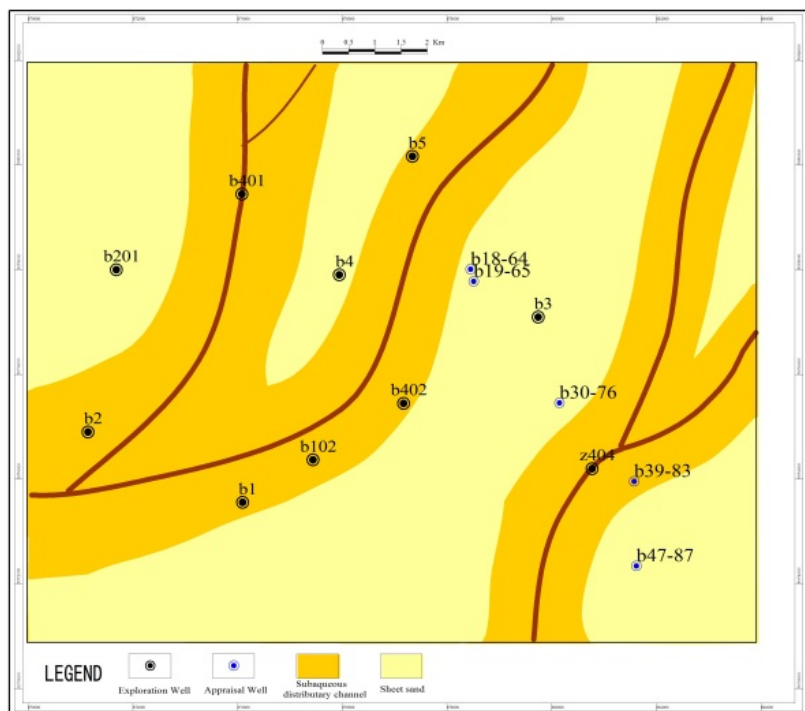

Fig. 11 Plain facies of F I 1 sub-layer

\section{Summary}

1. Fuyu oil layer can be divided into three mid-term cycles and further divided into five short-term cycles. FIII, F II , F I 3 and F I 2 sub-layer of Fuyu oil layer in research area is mainly Delta plain deposition, the micro facies include distributary channel, crevasse splay, natural levee and mud between distributary channel; F I 1 sub-layer is mainly Delta front deposition, the micro facies include subaqueous distributary channel and sheet sand, lack of channel mouth bar.

2. During the sedimentary period of FIII, F II and F I 3 sub-layer, the climate changed from humid to dry, water level gradually became shallower, sediment supply increased; During the sedimentary period of F I 2 and F I 1 sub-layer, the climate changed from dry to humid, the lake basin range expanded, water level gradually became deeper, sediment supply gradually decreased in the research area. 


\section{References}

[1] Mingyi Hu, Chunyan Sun, Dan Xue, Hongjun Zhang. Study of high resolution sequence stratigraphy of Quan 4th member, Sanzhao area in the northern Songliao Basin. GEOSCIENCE. 2015, 29(4), 765-776.

[2] Yuanlin Chi, Deming Xiao, Jinyin Yin. The injection pattern of oil and gas migration and accumulation in the Sanzhao area of Songliao Basin. Acta Geologia Sinica. 2000, 74(4), 371-377.

[3] hongwen Deng, Haibo Wu, Ning Wang, Timothy A. Cross. Division of fluvial sequence stratigraphy - an example from the Lower Cretaceous Fuyu oil layer, Songliao Basin. OIL \& GAS GEOLOGY. 2007, 28(5).

[4] Kebao Zhang, Hongbin Zhang, Yuguang Zhao, Xiaosong He, Zhihua Sun. RMS amplitude and Lithology. Oil Geophysical Prospecting. 2007, 42, 93-96. 